\section{ANÁLISE DE CONTEÚDO NA INVESTIGAÇÃO PEDAGÓGICA EM EDUCAÇÃO FÍSICA: ESTUDO SOBRE ESTÁGIO CURRICULAR SUPERVISIONADO}

\author{
CONTENT ANALYSIS IN EDUCATIONAL RESEARCH IN PHYSICAL \\ EDUCATION: A STUDY ON CURRICULAR INTERNSHIP
}

ANÁLISIS DE CONTENIDO EN INVESTIGACIÓN PEDAGÓGICA EN EDUCACIÓN FISICA: ESTUDIO SOBRE LA PRÁCTICA CURRICULAR CURRICULAR SUPERVISADA

Larissa Cerignoni Benites*, Juarez Vieira do Nascimento**, Michel Milistetd***, Gelcemar Oliveira Farias ${ }^{\star \star * *}$

\section{Palavras-chave}

Estágios.

Pesquisa qualitativa.

Ensino.

Docentes.

Keywords

Internship.

Qualitative research

Teaching.

Teachers.

Palabras clave

Prácticas

curriculares.

Investigación

cualitativa.

Enseñanza.

Docentes.
Resumo: 0 objetivo do presente estudo é evidenciar o passo a passo de uma pesquisa sobre formação de professores, no contexto do estágio curricular supervisionado em Educação Física, através de procedimentos de análise de conteúdo. Considerando as fases da análise de conteúdo, orientadas por Bardin (1979) - pré-análise, exploração do material, tratamento dos resultados, inferência e interpretação -, descreve-se, detalhadamente, o caminho adotado pelos pesquisadores no processo de compreensão da interlocução entre escola, professor-colaborador e estagiário.

Abstract: This article is a step-by-step description of a study on teacher training in the context of curricular supervised internship in Physical Education. Using Bardin's (1979) content analysis procedures - pre-analysis, exploration of material, result processing, inference, and interpretation - it describes in detail the pathway adopted by researchers in the process of understanding the dialogue between school, assistant teacher, and student.

Resumen: El objetivo de este estudio es mostrar el paso a paso de una investigación sobre formación de docentes en el contexto de la práctica curricular supervisada en Educación Física, a través de procedimientos de análisis de contenido. Considerando las etapas del análisis de contenido, orientadas por Bardin (1979) -a saber, preanálisis, exploración del material, procesamiento de los resultados, inferencia e interpretación- se describe en detalle el camino adoptado por los investigadores en el proceso de comprensión del diálogo entre escuela, profesor colaborador y estudiante en práctica.
* Universidade Estadual Paulista. Campus Rio Claro (UNESP). Rio Claro, SP, Brasil.

E-mail: Ibenites@rc.unesp.br

** Universidade Federal de Santa Catarina (UFSC). Florianópolis, SC, Brasil.

E-mail: juarez.nascimento@ufsc.br

*** Universidade Estadual do CentroOeste (UNICENTRO). Guarapava, PR, Brasil.

E-mail: michel_canhoto@ hotmail.com

**** Universidade do Estado de Santa Catarina (UDESC). Florianópolis, SC, Brasil.

E-mail: fariasgel@hotmail.com

Recebido em: 10-02-2015 Aprovado em: 30-09-2015

(c) (1) (8) Licence 


\section{INTRODUÇÃO}

Um dos desafios da investigação qualitativa é preencher de sentido as características que circundam um fenômeno social e que consistem em um conjunto de práticas interpretativas que tornam o mundo visível (DENZIN; LINCOLN, 2011). Embora os estudos com abordagem quantitativa sejam predominantes na área da Educação Física, investigações com abordagem qualitativa têm sido realizadas no intuito de melhor compreender esse campo do conhecimento, tanto no que se refere aos processos de coleta de dados (QUEIRÓS; LACERDA, 2013) como aos métodos de pesquisa (CASTRO; MORGAM; MESQUISTA, 2013, BATISTA, ALVES, 2013), caracterizando 0 contexto da área acadêmico-profissional, os interlocutores da ação e os campos de prática.

Nesse processo de significação de informações, a análise dos dados de estudos qualitativos ocupa papel fulcral, pois, independentemente das características do conteúdo explorado, a forma como se interpreta o material de pesquisa determina os caminhos que os resultados tomam (FLICK, 2014). Não obstante, as investigações com essa abordagem permitem que o pesquisador aprofunde as discussões através da interpretação e da análise dos dados coletados.

Com a proliferação e a utilização de novos recursos tecnológicos, o campo da análise qualitativa se mantém em constante evolução pelo aprimoramento de alguns métodos ou pelo surgimento de outros. Entre as novas tendências, destacam-se as análises de dados visuais e sonoros (JONES et al., 2013, MAEDER, 2014, KNOBLAUCH; TUMA; SCHNETTLER, 2014), a análise de mídias (HODGETTS; CHAMBERLAIN, 2014) e dados virtuais (GRBICH, 2013), que permitem detalhar as informações do contexto de investigação. Contudo, o emprego de técnicas tradicionais ainda ocupa o foco central da interpretação de informações provenientes dos fenômenos sociais (FLICK, 2014).

Um aspecto a ressaltar é que a análise de conteúdo continua a ser uma das técnicas mais empregadas na pesquisa qualitativa. De acordo com Shreier (2012) e Queirós e Graça (2013), a análise de conteúdo surgiu na primeira metade do século XX, nos Estados Unidos, com o intuito de investigar conteúdos de meios de comunicação em uma perspectiva quantitativa. Sua introdução no universo das pesquisas qualitativas ocorreu nos anos de 1960, com a finalidade de encontrar uma significação profunda para a mensagem escrita. Ela é considerada um conjunto de técnicas para descrever e interpretar o conteúdo das palavras ou mesmo para descobrir o que há nas entrelinhas de um texto (ROCHA; DEUSDARÁ, 2005).

Laurence Bardin é um dos grandes nomes que difundiram a análise de conteúdo. Aautora utilizou a técnica na área de comunicação de massa, em uma investigação psicossociológica, tendo publicado um livro que se tornou referência na área, intitulado Análise de Conteúdo. Para Bardin (1979), a análise de conteúdo tem duas grandes funções: a primeira é explorar o conteúdo e descobrir novos elementos, a segunda é o aparecimento das hipóteses que servem como diretrizes para o encaminhamento da pesquisa, do retorno ao campo, tirando a "prova", ou seja, realmente apresentando o que se tem, com o devido rigor, solicitado pela ciência. A análise pode ser caracterizada pela abordagem indutiva e dedutiva (QUEIRÓS; GRAÇA, 2013).

Essa técnica mostra-se disseminada no ambiente acadêmico, com quantidade significativa de livros e de artigos que retratam suas fases e a maneira como pode ser desenvolvida. Entretanto, poucos são os estudos sobre a formação de professores na realidade brasileira que apresentam minucioso desenvolvimento através da análise de conteúdo, 
principalmente em termos tanto de seleção das unidades de registro e de contexto como de categorização. 0 presente estudo tem como objetivo evidenciar o passo a passo de uma pesquisa sobre formação de professores, no contexto do estágio curricular supervisionado em Educação Física, que utilizou a análise de conteúdo.

\section{DESENVOLVIMENTO DA ANÁLISE DE CONTEÚDO}

Os dados qualitativos apresentam grande força, e necessitam, por isso, de um período de condensação, apresentação, elaboração e verificação. $O$ enfoque da análise de conteúdo ocorre na comunicação verbal ou não verbal, ou seja, cartas, jornais, livros, relatos autobiográficos, gravações, entrevistas, diários, fotografias, vídeos, entre outros meios, são fontes de dados e expressam as representações sociais na qualidade de elaboração mental construídas sob condições contextuais (histórica, econômica e sociocultural) nas quais os emissores estão envolvidos.

Os dados chegam ao investigador em estado bruto, necessitando serem organizados, transcritos e transformados em uma produção textual, para então passarem pelo processo de decodificação das mensagens (MORAES, 1999):

O grande segredo das pesquisas qualitativas está em descobrir o significado dado às palavras, pois a maioria das análises e dos dados está na forma de palavras e são elas que deverão ser organizadas, reagrupadas e permitirão ao pesquisador checá-las, confrontá-las e construir modelos (MILES; HUBERMAN, 2007, p. 21, tradução nossa).

Inicia-se, assim, o processo de verificação prudente e de interpretação, tendo como objetivo compreender: o discurso propagado; o motivo que levou o participante a usar determinada palavra ou expressão; o significado dado (ROCHA; DEUSDARÁ, 2005). Dentre as técnicas de análise de conteúdo que permitem elaborar essa "significação" dos dados, destacam-se a Análise Qualitativa de Conteúdo (SCHREIER, 2012), a Análise Hierárquica de Conteúdo (SPARKES; SMITH, 2014) e a Análise de Conteúdo (BARDIN, 1979). Apesar das semelhanças observadas entre as distintas técnicas, a opção por uma delas se faz necessária, respeitando suas particularidades, a fim de alcançar consistência no desenvolvimento da análise dos dados.

Antes mesmo de iniciaro processo analítico, o pesquisadordeve estabeleceralguns critérios que influenciarão os procedimentos adotados para a análise dos dados. 0 estabelecimento do problema da pesquisa e a escolha pela base teórica que sustenta a investigação (seja declarada ou não) definem a lente através da qual o pesquisador interpretará os materiais recolhidos e, além disso, podem determinar a forma como os dados serão analisados (SCHREIER, 2012). $\mathrm{Na}$ análise dedutiva, o processo analítico é conduzido sobre um foco específico, por meio de categorias determinadas a priori. Essa forma de análise explicita um olhar mais detalhado do investigador sobre aspectos particulares dos dados (QUEIRÓS; GRAÇA, 2013). A análise indutiva ou a posteriori "[...] é usada em casos em que não se dispõe de teorias prévias sobre os fenômenos que se pretende estudar, ou se pretender explorar o fenómeno sem partir das teorias ou categorias analíticas predefinidas" (QUEIRÓS; GRAÇA, 2013, p. 123-124).

Na perspectiva de Bardin (1979), a análise de conteúdo deve ser desenvolvida, de modo contínuo e progressivo, em três fases: pré-análise; exploração do material; tratamento 
dos resultados, inferência e interpretação. Diferentes autores (CASTRO; ABS; SARRIERA, 2011, MOZZATO; GRZYBOVSKI, 2011, QUEIRÓS; GRAÇA, 2013), preocupados com os métodos de pesquisa e de análise dos dados, também utilizaram a classificação das etapas emitidas por Bardin para melhor especificar todo o processo de condução analítica

A pré-análise tem como objetivo organizar e sistematizar os materiais disponíveis para a pesquisa, cabendo aqui escolher os documentos, formular hipóteses e elaborar indicadores que possibilitarão discutir seus resultados (WANLIN, 2007). Nessa fase, realiza-se a chamada "leitura flutuante", que permite conhecer o documento, fazer anotações e obter algumas impressões. Após essa leitura, o documento é relido atentamente, procurando-se indícios que podem ter passado despercebidos na primeira leitura, propondo-se conexões com as hipóteses e objetivos da pesquisa.

Em seguida, passa-seao processo de edição, ou seja, de recorte de trechos ecomentários que possam ilustrar o que se pretende discutir, tendo o cuidado de não descontextualizá-los, ou seja, não tirá-los do contexto no qual foram mencionados. Essa fase é conhecida por sua exaustividade, pois o material é manipulado muitas vezes, a fim de se extrair o máximo de informações sobre o problema de pesquisa. Ressalta-se que a coleta das informações deve ser adquirida da mesma forma: se forem entrevistas, todas devem ser do mesmo tipo e seguir idêntico protocolo, embora cada participante possa mudar seu encaminhamento. Após esses processos, começam a aparecer os temas de análise, o chamado corpus da pesquisa (BARDIN, 1979).

$\mathrm{Na}$ exploração do material, o objetivo é compreender o significado dado pelos envolvidos no estudo ao corpus da pesquisa. Contempla a contagem de ideias repetidas, a enumeração de situações que aparecem mais de uma vez ou mesmo aquelas que estão completamente ausentes (WANLIN, 2007). Nessa fase, aparecem duas grandes nomenclaturas da análise de conteúdo: as unidades de registro e as unidades de contexto. De acordo com Queirós e Graça (2013), há ainda a unidade de enumeração.

As unidades de registro são palavras, frases ou temas repetidos ao longo dos textos e encontrados nos diferentes documentos analisados, os quais permitem traçar o perfil dos participantes e conhecer as convergências e divergências sobre algum ponto. Berelson (1984) e Queirós e Graça (2013) explicam que as unidades de registro podem ser uma frase simples ou composta ou mesmo a reunião de algumas ideias que podem fazer alusão ao que se investiga.

As unidades de contexto colocam em evidência onde ocorrem os eventos das unidades de registro. Como exemplo, Bardin (1979, p. 107) apresenta a análise de mensagens políticas, nas quais "palavras como liberdade, ordem, progresso, democracia e sociedade, têm necessidade de contexto para serem compreendidas no seu verdadeiro sentido". Em uma associação com a área de formação de professores, as unidades de registros podem ser palavras como rotinas escolares, comportamentos dos estudantes, papel dos professores; e a unidade de contexto, a escola, ou seja, o local que possibilita a incidência de determinados acontecimentos. A unidade de contexto configura-se, pois, como "[...] o segmento do texto mais vasto que inclui e enquadra a unidade de registro e permite a sua compreensão" (QUEIRÓS; GRAÇA, 2013, p. 130).

As unidades de enumeração contêm a unidade que permite quantificar as unidades de registro, ou seja, a frequência de ocorrência.

A última etapa compreende o tratamento dos resultados, inferência e interpretação. Ela é considerada a chave do processo na pesquisa qualitativa por contemplar as categorias de análise. Tais categorias reúnem o maior número possível de informações advindas das diversas 
fontes (observação, entrevista e questionário) e têm a intenção de relacionar e organizar os fatos naquilo que Bardin (1979) chama de categorização.

A categorização é uma operação de classificação de elementos constitutivos de um conjunto, por diferenciação e, seguidamente, por reagrupamento segundo gênero (analogia), com critérios previamente definidos. As categorias são rubricas ou classes, as quais reúnem um grupo de elementos (unidades de registro no caso da análise de conteúdo) sob um título genérico, agrupamento esse efetuado em razão dos caracteres comuns desses elementos. [...] A categorização é um processo de tipo estruturalista e comporta duas etapas:

- O inventário: isolar os elementos.

- A classificação: repartir os elementos, e, portanto, procurar ou impor uma certa organização as mensagens. (BARDIN, 1979, p.117-118).

As categorias dizem respeito às expectativas do investigador, aos objetivos da pesquisa, às questões norteadoras, às características da mensagem, à objetividade e à produtividade. Através da compilação de autores interessados nesta temática, Queirós e Graça (2013) selecionaram algumas das características que as categorias devem abrigar: pertinência e adequação; exaustividade ou inclusão; homogeneidade; inclusão mútua; objetividade. É, portanto, permitido ao pesquisador realizar inferências para a discussão (MORAES, 1999), cabendo-lhe interpretar, refletir e criticar as informações adquiridas, para além do conteúdo manifesto, porém contemplando aquilo que é latente.

Os recursos de informática têm sido utilizados nas sucessivas ações realizadas naanálise de conteúdo, aliando facilidades funcionais à flexibilidade do processo investigativo. Dentre os softwares disponíveis, destaca-se o uso frequente de Nvivo, QDAMniner, Hyperbase, Alceste, Atlas ti, AQUAD e o MAXQDA. Os diferentes softwares oferecem ao pesquisador condições de lidar melhor com a amplitude dos dados, principalmente na organização, na edição e no uso de ferramentas estatísticas, garantindo a otimização do tempo. Isso permite que o pesquisador se debruce com mais calma sobre a interpretação das intenções das palavras, a maneira como foram ditas, as entonações utilizadas, os gestos corporais propagados (SCELLES, 1997).

O percurso das etapas previstas por Bardin (1979) na análise de conteúdo pode ser visualizado na Figura 1, a qual apresenta de modo objetivo a sequência cronológica.

Figura 1 - Etapas da Análise de Conteúdo

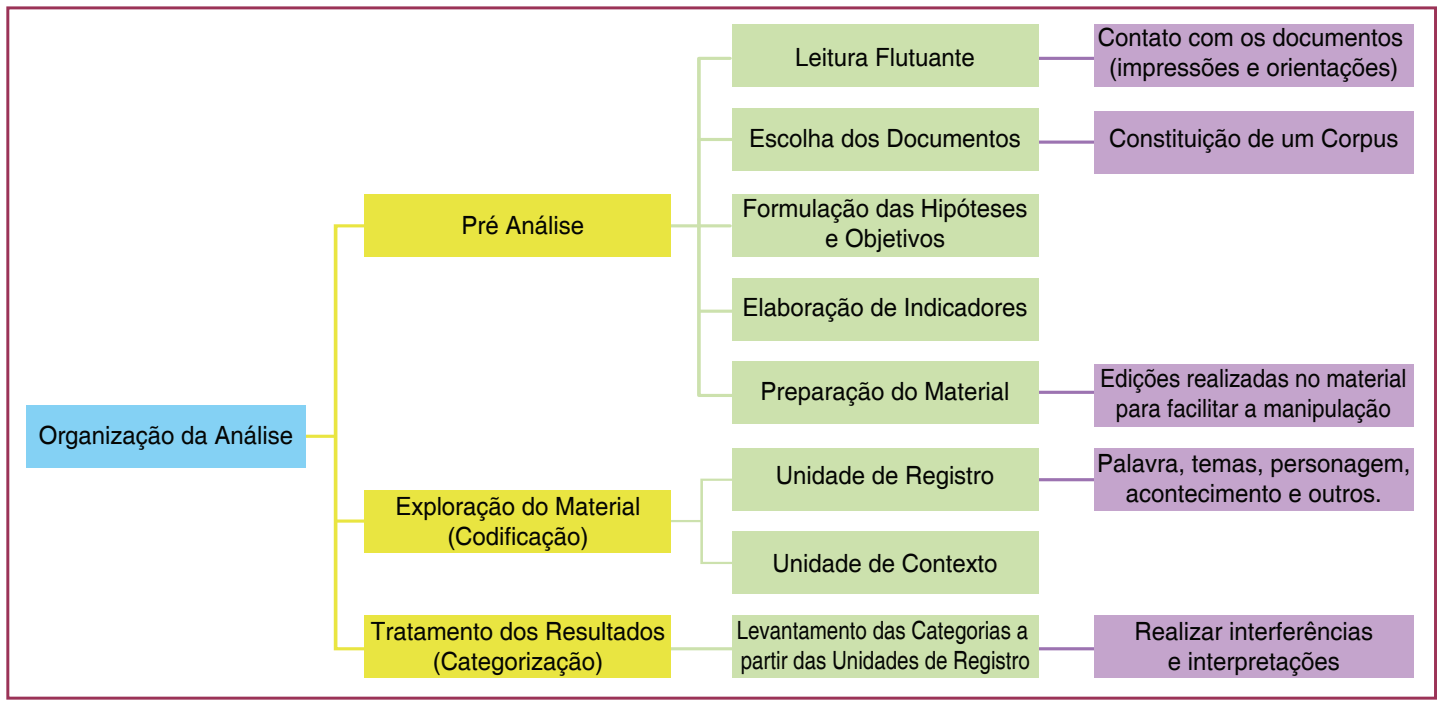


No Brasil, autores advindos das pesquisas qualitativas da formação de professores, como Ludke e André (1986), destacam a importância de encontrar as unidades de registro e de contexto para assegurar a etapa crucial da categorização. Esse é o momento em que se confronta a teoria com o processo empírico, detecta-se o que é regular e ponderase sobre o que os dados respondem ou não quanto aos objetivos da pesquisa. Para as autoras, os dados devem ser tratados com cuidado e atenção, devendo ser destrinchados para compor as categorias de maneira que se afunilem ao que é de suma importância. Quando se esgota a possibilidade de interação com o material coletado, chega-se ao fim da análise de conteúdo. Esta é uma técnica exigente, que requer maturidade por parte do pesquisador.

A preocupação em descrever os itinerários utilizados no processo de análise dos dados visa garantir a veracidade da pesquisa e dar suporte ao pesquisador na defesa de suas ideias (SCELLES,1997). Os especialistas em pesquisa qualitativa (MILES; HUBERMAN, 2007, DENZIN; LINCOLN, 2011, FLICK, 2014) destacam que, além do detalhamento do processo e da exaustividade na análise, a triangulação dos dados, a revisão em pares e a confirmação da categorização por experts são fundamentais para atingir a validade e a confiabilidade do processo analítico, atendendo todas as exigências que o processo investigativo envolve.

Encerradas todas as etapas, inicia-se o árduo trabalho da discussão dos resultados, que de alguma forma já vinha sendo alinhavado desde o tratamento dos dados. Contudo, nesse momento, o recorte proposto contempla a exemplificação das fases da análise de conteúdo em uma pesquisa específica.

O próximo tópico reporta-se ao desenvolvimento da análise de conteúdo em uma pesquisa qualitativa, do tipo construtivismo social, que abordou o estágio curricular supervisionado na formação de professores de Educação Física. Registram-se apontamentos sobre os objetivos da pesquisa e procedimentos utilizados que são de grande importância para a confecção da análise de dados.

\section{PROFESSOR-COLABORADOR NO ESTÁGIO CURRICULAR SUPERVISIONADO EM EDUCAÇÃO FÍSICA: PERFIL, PAPEL E POTENCIALIDADES}

A pesquisa realizada por Benites (2012) teve como questão central de estudo compreender como o professor-colaborador (professor da escola que recebe os estagiários em caráter oficial) torna-se um formador no âmbito do estágio. Os objetivos propostos foram: (a) caracterizar o espaço do estágio curricular supervisionado; (b) caracterizar o trabalho do professor-colaborador; (c) apontar quais saberes e práticas emergem do professor-colaborador no contexto do estágio.

Participaram do estudo cinco professores-colaboradores de Educação Física, de cinco escolas diferentes da cidade de Rio Claro, as quais, há mais de cinco anos, recebem estudantes em caráter oficial de estágio e nove estagiários do curso de licenciatura em Educação Física da Universidade Estadual Paulista, Campus Rio Claro - UNESP/RC. As técnicas utilizadas para a coleta de dados foram: fonte documental (curso de extensão e material produzido pela UNESP/ RC sobre o estágio), observação sistematizada (caderno de campo com filmagens totalizando 170 horas) e entrevista semiestruturada. Em todas as etapas foi solicitada a concordância dos 
participantes através da assinatura do termo de consentimento livre e esclarecido. A referida pesquisa foi aprovada pelo Comitê de Ética de Pesquisa com Seres Humanos da instituição. A análise ocorreu mediante os indicativos da análise de conteúdo.

Quadro 1- Distribuição de professores-colaboradores e estagiários por escola investigada

\begin{tabular}{|c|c|c|}
\hline Escola & Professor-colaborador & Estagiários \\
\hline 1 & 1 & $\mathrm{~A} \mathrm{e} \mathrm{B}$ \\
\hline 2 & 2 & $\mathrm{C}$ \\
\hline 3 & 3 & $\mathrm{D} \mathrm{e} \mathrm{E}$ \\
\hline 4 & 4 & $\mathrm{~F}, \mathrm{G} \mathrm{eH}$ \\
\hline 5 & 5 & $\mathrm{~J}$ \\
\hline
\end{tabular}

Fonte: Benites (2012, p.67).

A análise do conteúdo teve início com a pré-análise dos dados, durante a qual organizouse o material. Os primeiros documentos organizados foram os advindos da fonte documental. Tratava-se de cadernos de estágio; regulamentos da universidade para o acontecimento dos estágios; dados de um curso de extensão promovido para professores-colaboradores junto à Secretaria Municipal de Educação de Rio Claro; dados de um encontro com professorescolaboradores promovido na universidade.

Os documentos foram lidos e organizados por tópicos que respondessem aos objetivos da pesquisa. A primeira leitura permitiu que os documentos fossem sistematizados, de modo a apontar indícios que explicitassem o contexto em que ocorria 0 estágio e a perspectiva do professor-colaborador, respondendo prioritariamente aos dois primeiros objetivos da pesquisa.

Os dados advindos do trabalho de campo necessitaram passar por uma organização diferenciada, pois estavam em áudio ou imagem, o que exigiu sua transcrição. Os cadernos de campo foram digitados e as entrevistas individuais foram transcritas. Tais documentos retornaram para os sujeitos da pesquisa, para que validassem as declarações e emitissem seu aceite (NEGRINE, 2004).

Os vídeos passaram por um processo de edição de imagens. A edição teve como influência o olhar da pesquisadora, a qual privilegiou cenas que poderiam ser analisadas em relação a acontecimentos específicos, tais como o conflito entre estudantes, o auxílio do professor, a comunicação dos estagiários, as trocas de atividades, a relação entre alunosestagiários, a relação entre professor-colaborador e estagiário, entre outros pontos.

Cada escola teve o mínimo de oito e o máximo de 14 recortes das cenas filmadas. Com base nessas cenas, foi confeccionado, para cada escola, um roteiro para análise e discussão das imagens. Contudo, havia itens presentes em mais de uma unidade escolar, como se visualiza no Quadro 1. A hipótese é que algumas escolas trabalham com públicos-alvo semelhantes, em termos de nível de ensino, ou têm desafios parecidos. A ordem de apresentação das informações está de acordo com a proximidade entre os itens e não referenda a ordem de aparecimento nos respectivos roteiros. 
Quadro 2 - Análise das imagens do estudo

\begin{tabular}{|c|c|c|c|c|}
\hline ESCOLA 1 & ESCOLA 2 & ESCOLA 3 & ESCOLA 4 & ESCOLA 5 \\
\hline $\begin{array}{c}\text { Controle do tempo } \\
\text { e dos alunos no } \\
\text { espaço }\end{array}$ & $\begin{array}{l}\text { O comando das } \\
\text { atividades pelo } \\
\text { estagiário }\end{array}$ & $\begin{array}{c}\text { Controle do tempo } \\
\text { e dos alunos no } \\
\text { espaço }\end{array}$ & $\begin{array}{l}\text { O comando das } \\
\text { atividades pelo } \\
\text { estagiário }\end{array}$ & $\begin{array}{l}\text { Postura dos } \\
\text { estagiários }\end{array}$ \\
\hline $\begin{array}{l}\text { Atenção dos } \\
\text { alunos }\end{array}$ & Motivação & $\begin{array}{l}\text { Atenção dos } \\
\text { alunos }\end{array}$ & $\begin{array}{l}\text { Conceitos } \\
\text { trabalhados }\end{array}$ & Motivação \\
\hline $\begin{array}{l}\text { Participação dos } \\
\text { alunos na atividade }\end{array}$ & $\begin{array}{l}\text { Comunicação } \\
\text { das atividades } \\
\text { desenvolvidas }\end{array}$ & $\begin{array}{l}\text { Comunicação } \\
\text { das atividades } \\
\text { desenvolvidas }\end{array}$ & $\begin{array}{l}\text { Comunicação } \\
\text { das atividades } \\
\text { desenvolvidas }\end{array}$ & $\begin{array}{l}\text { Participação dos } \\
\text { alunos na atividade }\end{array}$ \\
\hline $\begin{array}{c}\text { Auxílio professor- } \\
\text { estagiário }\end{array}$ & $\begin{array}{c}\text { Auxílio professor- } \\
\text { estagiário }\end{array}$ & $\begin{array}{c}\text { Auxílio professor- } \\
\text { estagiário }\end{array}$ & $\begin{array}{c}\text { Compreensão das } \\
\text { regras }\end{array}$ & $\begin{array}{c}\text { Auxílio professor- } \\
\text { estagiário }\end{array}$ \\
\hline $\begin{array}{l}\text { Local para as } \\
\text { aulas }\end{array}$ & $\begin{array}{l}\text { Diferença entre } \\
\text { turmas }\end{array}$ & $\begin{array}{l}\text { Local para as } \\
\text { aulas }\end{array}$ & $\begin{array}{c}\text { Diferença entre } \\
\text { turmas }\end{array}$ & $\begin{array}{l}\text { Ensino- } \\
\text { aprendizagem }\end{array}$ \\
\hline $\begin{array}{l}\text { Critérios de } \\
\text { segurança }\end{array}$ & $\begin{array}{c}\text { Dinâmica da aula: } \\
\text { participação e } \\
\text { competição }\end{array}$ & $\begin{array}{l}\text { Resolução de } \\
\text { problemas }\end{array}$ & $\begin{array}{l}\text { Resolução de } \\
\text { problema }\end{array}$ & Voz de comando \\
\hline $\begin{array}{l}\text { Controle da } \\
\text { atividade }\end{array}$ & $\begin{array}{c}\text { Organização das } \\
\text { atividades }\end{array}$ & & $\begin{array}{l}\text { Controle da } \\
\text { atividade }\end{array}$ & \\
\hline
\end{tabular}

Fonte: Benites (2012, p.74).

Essa foi a primeira organização do material de vídeo. Ela possibilitou chegar ao roteiro e, então, voltar ao campo, de modo a realizar as entrevistas sobre o conteúdo do vídeo tanto com os estagiários como com os professores-colaboradores. As entrevistas foram transcritas de modo a compor os documentos de análise.

Esse procedimento é justificado por Negrine (2004) na validação das declarações das entrevistas. Essa conduta tem sido adotada para assegurar maior rigor metodológico nos estudos qualitativos.

Salienta-se, pois, tanto a importância, na orientação do trabalho, da pré-análise com dados advindos de diferentes fontes como da maneira de organizá-los para serem apresentados, assim como a percepção de sua relação com os objetivos da pesquisa.

Em seguida, passou-se à fase da exploração do material (codificação). Iniciou-se a segunda leitura das fontes documentais, o que permitiu a seleção de trechos e as edições que a pesquisadora julgou serem apropriadas ao contexto da pesquisa. Esse processo é um dos mais delicados, pois o pesquisador deve se manter firme em seus propósitos de responder os objetivos da pesquisa, evitando ser seduzido pelos dados.

Devido à quantidade de dados, os quais, nesse momento, já se encontravam em formato de texto, utilizou-se o software QDAMiner para auxiliar esta fase da análise. Esse software é considerado de fácil utilização e com um design simples ao usuário, além de ter baixo custo no mercado (MORO; SANCHEZ-CRIADO, 2005). Quando todos os documentos foram alocados no software, iniciou-se o processo de leitura e recorte de trechos. Cada material teve, no mínimo, quatro leituras constituindo um corpus. 
O uso de software no processo de análise de dados não elimina o olhar atento do pesquisador sobre tal processo. O software configura-se como um auxílio, ao possibilitar dinamismo na organização dos dados e idas e vindas aos recortes, às escolhas e à categorização. Ele não se vincula a nenhum tipo de análise de dados, embora traga recursos para diferentes abordagens. É necessário, portanto, que o pesquisador tenha conhecimento da análise a que se propõe para tirar melhor proveito dos dados. Investigações na área da Educação Física (FARIAS, 2010; ROCHA, 2012; MOLETTA, 2013), que utilizam softwares para a análise de dados e que investigam a docência e a formação inicial em Educação Física, têm divulgado dados significativos para a produção do conhecimento da área.

Nesse momento do estudo, foi possível registrar: tópicos que se destacavam na mensagem; repetição de ideias; frequência de determinadas palavras. Assim se evidenciaram as chamadas unidades de registro (unidades que aglutinam trechos e/ou palavras que se interligam) e unidades de contexto (unidades que abrangem as unidades de registros afins), possibilitando, a partir desse movimento, pensar em engendrar categorias (Figura 2).

Figura 2: - Registro e frequência de palavras para o processo de análise de conteúdo

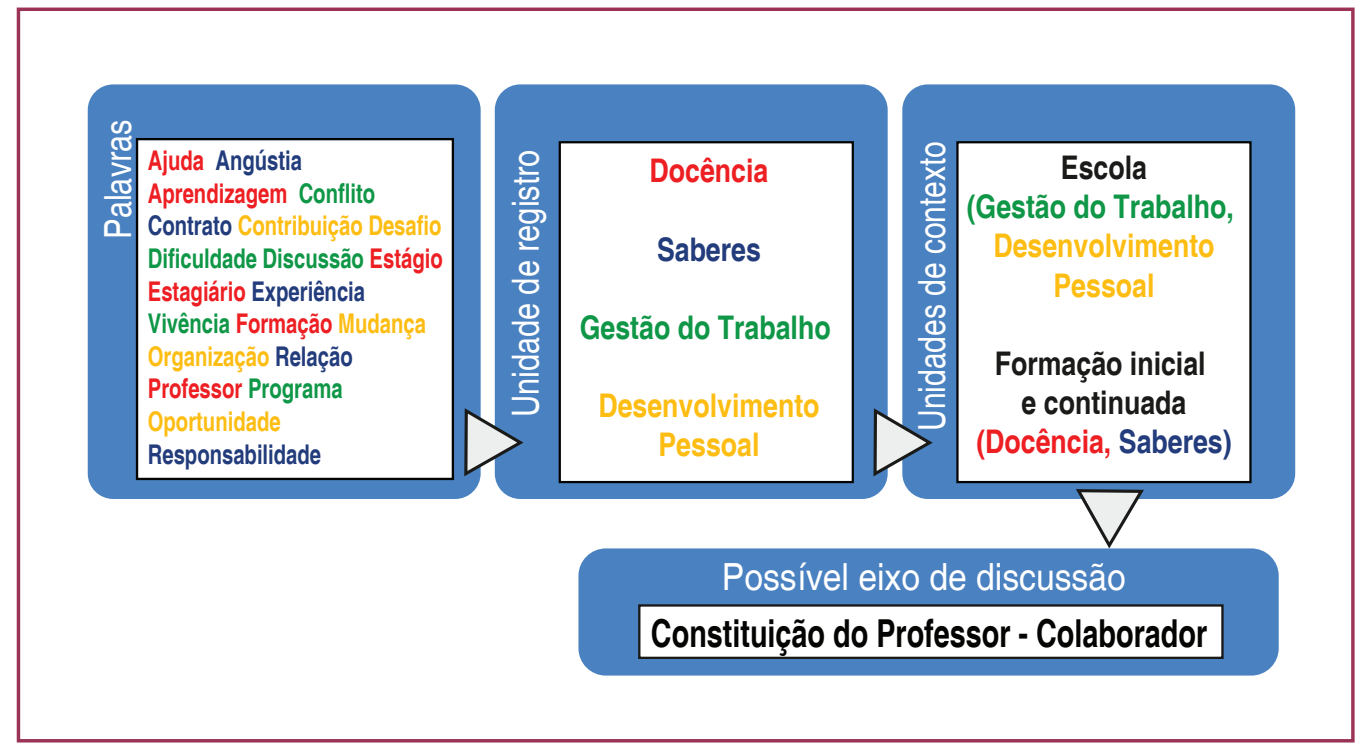

Fonte: Benites, Cyrino e Benites (2014, p. 1796)

Apesar de terem sido encontradas muitas unidades de registro, as unidades de contexto acabavam sendo as mesmas, proporcionando diferentes conotações ao trabalho. Por exemplo: a escola (uma unidade de contexto) - ora ela era mencionada como um local de ensino para os estudantes, ora como espaço de formação para os futuros professores.

A segunda fase da análise de conteúdo permitiu identificar a contribuição de cada material e a perspectiva que evidenciavam. A observação trouxe algumas informações quanto ao ambiente de prática, ao perfil de professor, às atividades desenvolvidas. A fonte documental incidiu sobre a visão do estágio. As entrevistas em vídeos abarcaram um pouco da condução do estágio e dos conflitos existentes durante as aulas. A entrevista individual reportou-se à trajetória profissional e às experiências de estágio (Figura 3). 
Figura 3 - Fontes de informação do estudo

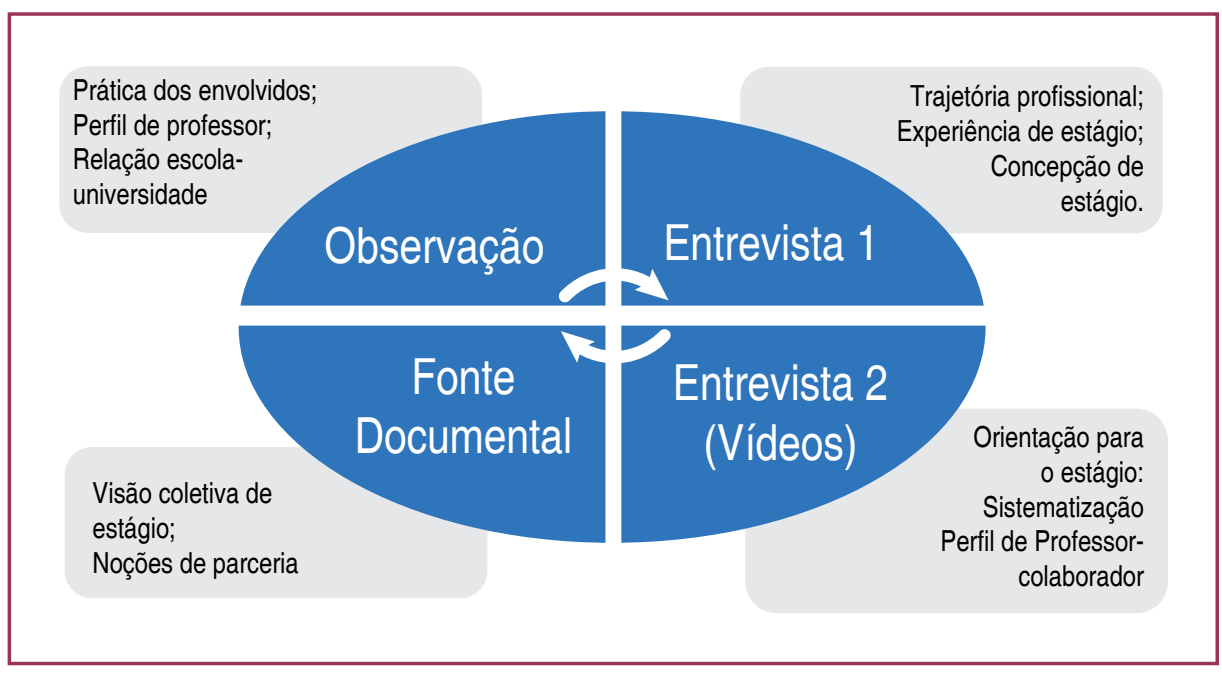

Fonte: Benites (2012, p. 78)

Para finalizar, chegou-se à terceira fase da análise de conteúdo, o tratamento dos resultados (categorização). Aqui, o primeiro passo foi analisar como as informações se coadunavam com os objetivos do trabalho para só então começar o processo de aglutinação (Figura 4).

Figura 4 - Relação entre as informações e os objetivos

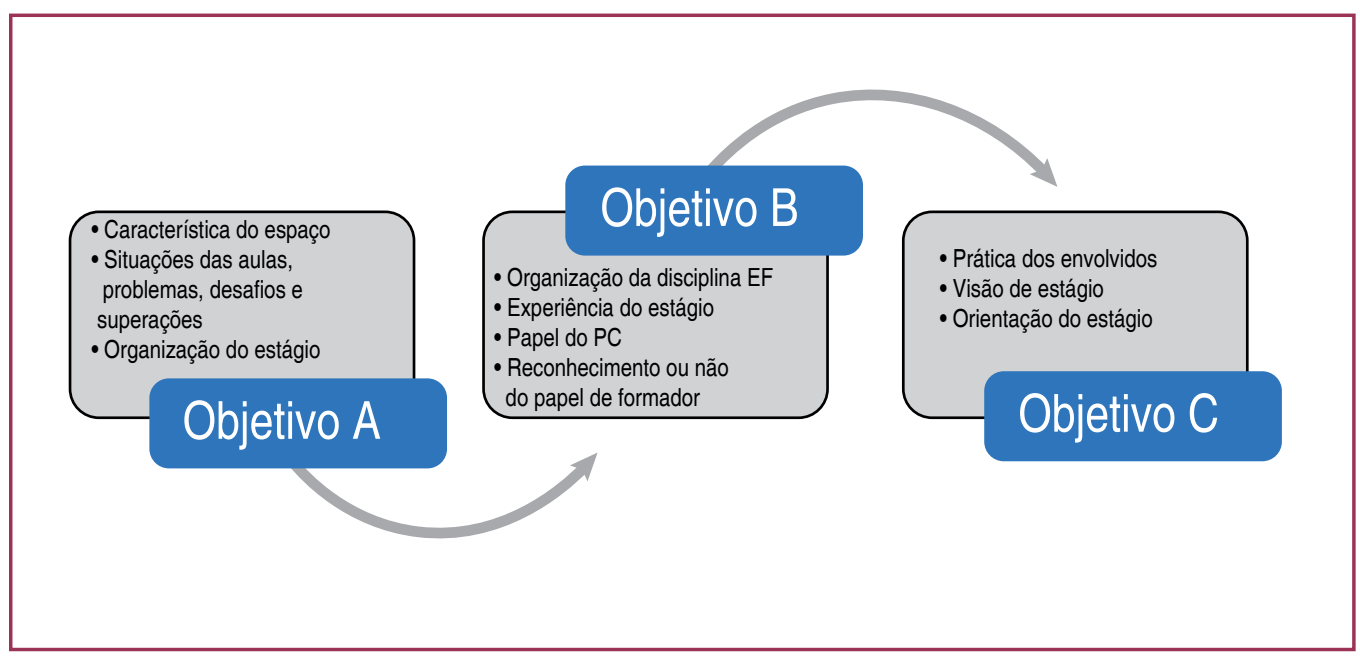

Fonte: Benites (2012, p.79)

0 processo de tratamento dos resultados, inferências e interpretações, neste momento do estudo, possibilitou a construção de categorias e subcategorias relativas a cada um dos materiais. Optou-se por utilizar os dados advindos dos documentos da instituição para corroborar um dos capítulos da pesquisa, denominado "Contexto", resultando no Quadro 3. 
Quadro 3 - Categorias e subcategorias

\begin{tabular}{|c|c|c|c|}
\hline Vídeos Estagiários & $\begin{array}{l}\text { Vídeos Professor- } \\
\text { Colaborador }\end{array}$ & $\begin{array}{l}\text { Entrevista Professor- } \\
\text { Colaborador }\end{array}$ & $\begin{array}{l}\text { Encontro Professor- } \\
\text { Colaborador }\end{array}$ \\
\hline $\begin{array}{l}\text { 1) Aulas } \\
\text { 1.1- As características } \\
\text { da turma } \\
\text { 1.2- Comunicação } \\
\text { 1.3- Problemas } \\
\text { 1.4- Superação }\end{array}$ & $\begin{array}{l}\text { 1) Aulas } \\
\text { 1.1- Alunos } \\
\text { 1.2- Problemas } \\
\text { 1.3- Supervisão } \\
\text { 1.4- Estratégias }\end{array}$ & $\begin{array}{l}\text { 1) Profissão } \\
\text { 1.1- Escolha } \\
\text { 1.2- Influências }\end{array}$ & $\begin{array}{l}\text { 1) Objetivo do grupo } \\
\text { 1.1- Para o supervisor } \\
\text { 1.2- Para o colaborador }\end{array}$ \\
\hline $\begin{array}{l}\text { 2) Feedback } \\
\text { 2.1- Pelo vídeo } \\
\text { 2.2- Pelo Prof-Col }\end{array}$ & $\begin{array}{l}\text { 2) Feedback } \\
\text { 2.1- Pelo vídeo } \\
\text { 2.2- Pelo Prof-Col }\end{array}$ & $\begin{array}{l}\text { 2) Estágio na formação } \\
\text { inicial } \\
2.1 \text { - Visão do estágio (1) } \\
\text { 2.2- Desenvolvimento } \\
\text { 2.3- Relação com a } \\
\text { universidade } \\
\text { 2.4- Relação com o } \\
\text { mercado de trabalho }\end{array}$ & $\begin{array}{l}\text { 2) Visão de Estágio } \\
\text { 2.1- Para o supervisor } \\
\text { 2.2- Para o colaborador }\end{array}$ \\
\hline $\begin{array}{l}\text { 3) Reflexões } \\
\text { 3.1- Mudança de } \\
\text { concepção } \\
\text { 3.2- Papel Prof-Col } \\
\text { 3.3- Relação Prof-Col }\end{array}$ & $\begin{array}{l}\text { 3) Experiência do estágio } \\
\text { 3.1 Para o estagiário } \\
\text { 3.2- Percepção do } \\
\text { momento } \\
\text { 3.3- Possibilidades }\end{array}$ & $\begin{array}{l}\text { 3) Início da carreira } \\
\text { 3.1- Dificuldades } \\
\text { 3.2- Superações }\end{array}$ & $\begin{array}{l}\text { 3) Possibilidade } \\
\text { 3.1- Parceria }\end{array}$ \\
\hline \multirow[t]{4}{*}{$\begin{array}{l}\text { 4) Experiência de } \\
\text { estágio } \\
\text { 4.1- Importância } \\
\text { 4.2- O processo } \\
\text { 4.3- Descobertas }\end{array}$} & & $\begin{array}{l}\text { 4) Ser Prof-Col } \\
\text { 4.1- Desde quando } \\
\text { recebe os estagiários } \\
\text { 4.2- Visão do estágio } \\
\text { 4.3- Como orienta } \\
\text { 4.4- Papel }\end{array}$ & $\begin{array}{l}\text { 4) Estágio } \\
\text { 4.1- Políticas Públicas }\end{array}$ \\
\hline & & $\begin{array}{l}\text { 5) Estagiários } \\
\text { 5.1- Perfil } \\
\text { 5.2- Relação }\end{array}$ & $\begin{array}{l}\text { 5) Imagem } \\
\text { 5.1- Da escola } \\
\text { 5.2- Do Professor }\end{array}$ \\
\hline & & $\begin{array}{l}\text { 6) Universidade } \\
\text { 6.1- Relação }\end{array}$ & \\
\hline & & $\begin{array}{l}\text { 7) Escola } \\
7.1 \text { - O processo de } \\
\text { estágio } \\
\text { 7.2- Espaço de informação }\end{array}$ & \\
\hline
\end{tabular}

Fonte: Benites (2012, p.81)

Ao aglutinar todos os itens evidenciados por essas categorias, chegou-se a três grandes eixos que conduziram a apresentação e a discussão dos resultados (Quadro 3). Os três eixos tendem a se ramificar em subitens em seu interior, devido à abrangência do fenômeno estudado: (1) o universo do estágio; (2) a constituição do professor-colaborador; (3) a orientação durante o estágio. 
Quadro 4 - Eixos que demarcam os resultados do estudo

\begin{tabular}{|l|l|l|}
\hline \multicolumn{1}{|c|}{ Universo do Estágio } & \multicolumn{1}{|c|}{$\begin{array}{c}\text { Constituição do } \\
\text { Professor- Colaborador }\end{array}$} & \multicolumn{1}{|c|}{$\begin{array}{c}\text { Orientação durante } \\
\text { o estágio }\end{array}$} \\
\hline 1) As aulas & 3) Reflexões & 2) Feedback \\
1.1- As características da turma. & 3.2- Papel do Prof-Col. & 2.1- Pelo vídeo \\
1.2- Comunicação & 3.3- Relação como o Prof-Col. & 2.2- Pelo Prof-Col. \\
1.3- Problemas & 3) Experiência de estágio & 1) As aulas \\
1.4- Superação & 3.2- Percepção do momento & 1.1- Os alunos \\
3) Reflexões & 5) Imagem & 1.2- Problemas \\
3.1- Mudança de concepção & 5.2- Do professor & 1.3- Superação \\
4) Experiência de estágio & 1) Profissão & 1.4- Estratégias \\
4.1- Importância & 1.1- Escolha & 2) Feedback \\
4.2- O processo & 1.2- Influências & 2.1- pelo vídeo \\
4.3-Descobertas & 2) Estágio na formação inicial & 2.2- pelo Prof-Col. \\
3) Experiência de estágio & 2.4- Relação com o mercado de & 3) Experiência de estágio \\
3.1-Para o estagiário & trabalho & 3.3- Possibilidades \\
1) Objetivo do grupo & 3) Ińcio de Carreira & 5) Imagem \\
1.1- Para o supervisor & 3.1- Dificuldades & 5.1- Da escola \\
1.2- Para o colaborador & 3.2- Superações & 4) Ser Prof-Col. \\
2) Visão do estágio & 4) Ser Prof-Col. & 4.3- Como orienta \\
2.1- Para o supervisor & 4.1- Desde quando recebe & 5) Estagiários \\
2.2- Para o colaborador & estagiários & 5.2- Relação \\
3) Possibilidade & 4.2- Papel & \\
3.1- Parceria & & \\
4) Estágio & & \\
4.1- Políticas Públicas & & \\
2) Estágio na formação inicial & & \\
2.1- Visão de estágio (1) & & \\
2.2- Desenvolvimento & & \\
2.3- Relação com a universidade & & \\
4) Ser Prof-Col. & & \\
4.1- Visão de estágio (2) & & \\
5) Estagiários & & \\
5.1- Perfil & & \\
6) Universidade & & \\
6.1- Relação & & \\
7) Escola & & \\
7.1- O processo de estágio & & \\
7.2- Espaço de formação & & \\
\hline
\end{tabular}

Fonte: Benites (2012, p.82)

No primeiro eixo, denominado universo do estágio, a expectativa era apresentar como é o estágio, qual seu espaço, como são as características de cada lugar, como se dão as rotinas, aventurar-se sobre a relação entre a universidade e a escola e o tipo de desafios enfrentados. $O$ segundo eixo contemplou a constituição do professor-colaborador. Ele visou mostrar como os estagiários visualizam a figura do professor-colaborador, como o próprio professor concebe essa função, quais as crenças pessoais sobre o estágio e a importância desse momento na formação do futuro professor. O terceiro eixo concentrou- se na orientação durante o estágio, abordando a maneira como o professor-colaborador orienta, como se relaciona com o estagiário na tentativa de evidenciar saberes e práticas.

Iniciaram-se então a apresentação e a discussão dos resultados. Verificou-se que o estudo atingiu seus objetivos, mostrando ser o estágio um espaço que congrega tanto o discurso acadêmico como a prática da escola, constituindo-se também como um local 
de formação que apresenta, porém, determinadas dificuldades em reconhecer esse papel. O professor-colaborador foi compreendido como alguém formado para ser professor, mas que, em determinado momento de sua carreira, passa a receber estagiários quer por boa vontade, quer por camaradagem. Os saberes que ele possui são evidenciados por meio de posturas e gestos, tendo o saber experiencial como polo de conhecimento para a orientação de suas ações.

Houve ganhos quando se pensa na estratégia de análise adotada, pois ela permitiu decifrar as mensagens viabilizadas em entrevistas, fontes documentais e vídeos. 0 protocolo de análise mostrou-se oportuno em relação a princípios conceituais, tais como credibilidade ${ }^{1}$ (resultados que sejam plausíveis para os sujeitos envolvidos); transferibilidade (que os resultados possam ser transferidos para outros contextos ou pelo menos suscitem a discussão); consistência (que os resultados permaneçam estáveis com o passar dos anos).

Durante as fases da análise de conteúdo, registraram-se, contudo, dificuldades em se manter atento aos objetivos e em ser coerente com o problema da pesquisa. 0 estudo é um todo que interliga diferentes fontes de informação e análise de dados, cujos passos e protocolos servem para orientar o encontro das vias, podendo ser árduo e exaustivo. A opção de se manter atento aos objetivos do estudo pareceu ser um bom caminho, partindo daí as hipóteses, as questões e as interpretações que possibilitaram discutir os dados encontrados, sendo, porém, impossível não deixar rastros do pesquisador durante sua construção.

\section{CONSIDERAÇÕES FINAIS}

0 processo de análise de dados na pesquisa qualitativa pode ser considerado 0 coração do sistema, uma parte imprescindível para a descoberta de elementos que poderão responder aos objetivos e ao problema de estudo, especialmente na investigação pedagógica em Educação Física. Para auxiliar tal processo, o uso de software foi essencial. Por exemplo, o QDAMiner dinamizou e organizou o trabalho com as unidades de registro e de contexto, permitindo manejar os dados de maneira mais veloz. Contudo, é imprescindível o contato com o tipo de análise evocada por parte do pesquisador.

A fim de elucidar o modo como as pesquisas qualitativas podem se valer da análise de conteúdo, os procedimentos adotados e os principais resultados encontrados em uma pesquisa desta natureza foram apresentados. Foram evidenciados também a maneira como tal pesquisa se beneficiou da contribuição da análise de conteúdo, as sequências utilizadas, os procedimentos adotados e alguns encaminhamentos. A pesquisa passou pelas fases de préanálise, exploração do material e tratamento dos resultados, revelando distinções com relação à elaboração de indicadores e ao levantamento de categorias, priorizando o retorno constante aos objetivos e a reorientação de suas categorias.

Durante todo o processo investigativo, salientaram-se três aspectos. Primeiro, a ideia de rigor necessário para os protocolos e os procedimentos adotados com os materiais. Segundo, a difícil noção de neutralidade do pesquisador frente aos dados para que estes possam ser considerados fidedignos. Terceiro, a maturidade necessária ao pesquisador, indicando que a experiência de pesquisa, o tempo de contato com os dados e o fato de trabalhar com diferentes instrumentos de coleta aos poucos proporcionam ao pesquisador condições para compreender

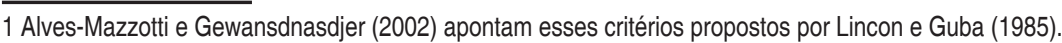


a complexidade da análise, prestar atenção em seu teor e revisitar suas ideias. De modo geral, os três aspectos possibilitam ter maior clareza do processo, tornando possível esclarecer o passo a passo efetuado e explicitar os procedimentos adotados.

Em síntese, registra-se que a análise do conteúdo é um dos tipos de análise existentes no processo de tratamento dos dados de pesquisas qualitativas, e, todavia, apresenta limites. Por exemplo, prevê tempo e experiência na pesquisa para que os dados possam, de fato, ter valor e significado, exige também que o pesquisador faça leituras aprofundadas sobre o tema da investigação.

Este relato concentrou-se na apresentação dos encaminhamentos da pesquisa qualitativa quanto ao uso da análise de conteúdo na investigação sobre os estágios na formação de professores em Educação Física. Fica o convite para que outros pesquisadores apresentem seus "caminhos das pedras".

\section{REFERÊNCIAS}

ALVES-MAZZOTTI, Alda J.; GEWANDSZNADJDER, Fernando. 0 método nas ciências naturais e sociais: pesquisa quantitativa e qualitativa. São Paulo: Pioneiras, 2002.

BARDIN, Lawrence. Análise de conteúdo. Lisboa: Edições 70, 1979.

BATISTA, Paula; ALVES, M. A etnografia. In: MESQUITA, Isabel; GRAÇA, Amandio. (Org.). Investigação qualitativa em desporto. Porto: Porto, 2013. v. 1, p. 153-195.

BENITES, Larissa C. Formação do professor-colaborador: a "prática de ensino" na educação física. 180f. Tese (Doutorado em Ciência da Motricidade) - Instituto de Biociências, Universidade Estadual Paulista, Rio Claro, 2012.

BENITES, Vanessa C. Formação de professores de matemática: dimensões presentes na relação PIBID e comunidade de prática. Dissertação (Mestrado em Educação Matemática) - Instituto de Geociências e Ciências Exatas, Universidade Estadual Paulista, Rio Claro, 2013.

BENITES, Larissa C.; CYRINO, Marina; BENITES, Vanessa C. Algumas ideias sobre o uso da análise de conteúdo em pesquisas sobre formação de professores. In: II Congresso Nacional de Formação de Professores e XII Congresso Estadual Paulista sobre Formação de Educadores. Anais... Águas de Lindoia: UNESP/PROGRAD, 2014, p.1790-1802.

BERELSON, Bernard. Content analysis in communication research. New York: Hafner; 1984.

CAMPOS, Claudinei J. G. Método de análise de conteúdo: ferramenta para a análise de dados qualitativos no campo da saúde. Revista Brasileira de Enfermagem, Brasília, v. 57, n. 5, alvez611-42, set/out. 2004.

CASTRO, Tiago G.; ABS, Daniel; SARRIERA, Jorge C. Análise de conteúdo em pesquisas de psicologia. Psicologia: Ciência e Profissão, Brasília, v. 31, n. 4, p. 814-825, 2011.

CASTRO, José; MORGAM, Kevin; MESQUISTA, Isabel. Investigação-ação. In: MESQUITA, Isabel; GRAÇA, Amandio. (Org.). Investigação qualitativa em Desporto. Porto: Porto Editora, 2013. v. 1, p. 121-148.

DENZIN, Norman; LINCOLN, Yvonne. The SAGE handbook of qualitative research. London: Sage, 2011.

FARIAS, Gelcemar O. Carreira docente em educação física: uma abordagem na construção da trajetória profissional do professor. 2010. 303 f. Tese (Doutorado) - Programa de Pós Graduação em

Educação Física, Universidade Federal de Santa Catarina, Florianópolis, 2010. 
FLICK, Uwe. Mapping the field. In: FLICK, Uwe. The SAGE handbook of qualitative data analysis. London: Sage, 2014. p. 3-18.

GRBICH, Carol. Qualitative data analysis. 2nd London: Sage, 2013.

HODGETTS, Darrin; CHAMBERLAIN, Kerry. Analysing news media. In: FLICK, Uwe. The SAGE handbook of qualitative data analysis. London: SAGE, 2014. p. 380-393.

JONES, Robyn et al. Métodos visuais na investigação em coaching: capturando o cotidiano. In: MESQUITA, Isabel; GRAÇA, Amandio (Org.). Investigação qualitativa em desporto. Porto: Porto, 2013. v. 2, p. 153-172.

KNOBLAUCH, Hubert; TUMA, Rene; SCHNETTLER, Bernt. Video analysis and videography. In: FLICK, Uwe. The SAGE handbook of qualitative data analysis. London: SAGE, 2014. p. 435-449.

LUDKE, Menga; ANDRÉ, Marli E. D. A. Pesquisa em educação: abordagens qualitativas. São Paulo: EPU, 1986.

MAEDER, Christoph. Analyzing sounds. In: FLICK, Uwe. The SAGE handbook of qualitative data analysis. London: SAGE, 2014. p. 424, 423.

MILES, Matthew; HUBERMAN, Michael. Analyse des donnés qualitatives: méthodes en sciences humaines. Bruxelles: DeBoeck, 2007.

MOLETTA, Andrea F. Socialização profissional de professores de Educação Física do ensino superior. 2013. 169 f. Dissertação (Mestrado) - Programa de Pós Graduação em Educação Física, Universidade Federal de Santa Catarina, Florianópolis, 2013.

MORAES, Roque. Análise de conteúdo. Revista Educação, Porto Alegre, v. 22, n. 37, p. 7-32, 1999.

MORO, M.; SANCHEZ-CRIADO, Tomas. Taller de metodología de investigación: herramientas básicas para la investigación cualitativa: introducción al manejo del programa de análisis cualitativo QDA Miner 1.2. Madrid: UAM. 2005. Pt. 2.

MOZZATO, Anelise R; GRZYBOVSKI, Denize. Análise de Conteúdo como Técnica de Análise de Dados Qualitativos no Campo da Administração: Potencial e Desafios. RAC, Curitiba, v. 15, n. 4, p. 761-765, jul./ago. 2011.

NEGRINE, Airton. Instrumentos de coleta de informações na pesquisa qualitativa. In: MOLINA NETO, Vicente; TRIVIÑOS, Augusto. N. S. (Orgs.) A pesquisa qualitativa na Educação Física: alternativas metodológicas. Porto Alegre: Ed. Universidade/UFRGS/Sulina, 2004. p. 61-94.

QUEIRÓS, Paula; GRAÇA, Amandio. A análise de conteúdo (enquanto técnica de tratamento de informação) no âmbito da investigação qualitativa. In: MESQUITA, I; GRAÇA, A. (Org.). Investigação qualitativa em desporto. Porto: Porto, 2013. v. 2, p. 115-149.

QUEIRÓS, Paula; LACERDA, Teresa. A importância da entrevista na investigação qualitativa. In: MESQUITA, Isabel; GRAÇA, Amandio. (Org.). Investigação qualitativa em Desporto. Porto: Porto, 2013. v. 2, p. 177-206.

ROCHA, Julio C. S. As competências na formação do professor de educação física: um olhar acerca das atitudes. 2013. 208 f. Tese (Doutorado em Educação Física) - Programa de Pós Graduação em Educação Física, Universidade Federal de Santa Catarina, Florianópolis, 2013.

ROCHA, Décio; DEUSDARÁ, Bruno. Análise de conteúdo e análise do discurso: aproximações e afastamentos na (re)construção de uma trajetória. Alea, Rio de Janeiro, v. 7, n. 2, p. 305-322, jul./dez. 2005.

SCELLES, Régine. Apports de logiciels d'analyse de données textuelles (ADT) dans les procédures d'analyse de contenu d'entretiens semi-directifs de recherche: Alceste et hyperbase. Bulletin de Méthodologie Sociologique, Paris, p. 25-57, 1997. 
SCHREIER, Margrit. Qualitative content analysis in practice. London: Sage, 2012.

SPARKES, Andrew; SMITH, Brett. Qualitative research methods in sport, exercise and health: from process to product. London: Routledge, 2014.

WANLIN, Philippe. L'analyse de contenu comme méthode d'analyse qualitative d'entretiens : une comparaison entre les traitements manuels et l'utilisation de logiciels. Recherches Qualitatives, Québec, n. 3, p. 243-272, 2007. 